\title{
Time taken to escort men who have sex with men (MSM) for HIV testing in the peer group interventions in Sri Lanka
}

\author{
M. Suchira Suranga ${ }^{1}$, D. A. Karawita ${ }^{2}$, S.M.A.S. Bandara ${ }^{3}$, R. M. D. K. Rajakaruna ${ }^{4}$
}

\begin{abstract}
Introduction: Sri Lanka has completed a phase of an HIV prevention project (from 2013 to 2015) for men who have sex with men (MSM) under the support of Global Fund. The intervention was to deliver an HIV prevention package (HPP) to MSM which included provision of six services (1. STI knowledge, 2. HIV knowledge, 3. MSM tailored leaflets, 4. Condom/dildo demonstration, 5. Provision of condoms, and 6. Clinic escort). MSM who received all 1, 2, 3, 4 and 5 services in the HPP are defined as "reached". The final step is to escort the reached (who received initial 5 services) MSM to an STD clinic, and ones they are escorted they are defined as "escorted". This HPP was delivered to MSM through peer educators (PE) scattered in four high populous districts in the country. Each PE has regular contact with another 6-15 peers forming a peer group (PG). However, in this model, a significant number of MSM does not take the escorting step (step 6). Therefore, the purpose of this paper is to analyze the time taken to escort and other associated factors for an MSM to be escorted to an STD clinic.
\end{abstract}

Method: All the MSM peers (699 MSM) registered in 2013 and retained during the project till the end of December 2015 have been filtered out from the web-based monitoring and evaluation information management system (MEIMS) for analysis. Time-to escort analysis with Kaplan-Meier was performed to find out median escort time. Hypothesis testing for equality of survival distribution (Kaplan-Meier curve) was conducted to determine the differences in probabilities of first clinic escort for different socio-economic and demographic characteristics.

Results: Estimated median time-to escort was 17 months (SD = 0.867). Escorting is less likely with non-youth MSM ( $\geq 25$ years), educated MSM (> GCE O/L), rural MSM, Nachchi MSM (effeminate males), high frequent receptive MSM ( $\geq 7 /$ week) and high duration MSM ( $\geq 10$ years). Galle and Gampaha districts shows high performance in escorting compared to other districts

Conclusions: More vulnerable and high risk segments of MSM population are less likely to be escorted for HIV testing in the current programme design. Current intervention need to strengthen with more focus strategies to address this programmatic gap. In addition, performance of PEs, field supervisors and coordinators has been observed to be a major factor in improving escort rate.

Key words: Men who have sex with Men (MSM), HIV, time taken to escort, Escorts, Peer Education, Survival Analysis

\footnotetext{
Authors: corresponding author: ${ }^{1}$ Mr Suchira Suranga, M.Phil, M.Sc., B.Sc (sp) Hons, Deputy Director, Monitoring and Evaluation, The Family Planning Association of Sri Lanka.Email: suchirasuranga@gmail.com, suranga@fpasrilanka.org

${ }^{2}$ Dr Ajith Karawita, MBBS, PGD Ven, MD, MSLCV; Consultant Venereologist, Teaching Hospital, Anuradhapura

${ }^{3} \mathrm{Mr}$. Amal Bandara, M. Sc. (Reading), PGD in Development Studies, B.Sc (Nutrition), Monitoring and Evaluation Officer (Global Fund Project), The Family Planning Association of Sri Lanka

${ }^{4}$ Mr. Duminda Rajakaruna, MA (Sociology), BA (sp) Hons (Economics), Assistant Director, Monitoring and Evaluation, The Family Planning Association of Sri Lanka

Acknowledgement: Family Planning Association of Sri Lanka, Heart to Heart Lanka, Saviya Development Foundation, Dr. Ariyaratne Manathunge, Consultant Venereologist, National STD/AIDS Control Programme of Sri Lanka

Originality: This is an original work not published anywhere

Conflict of interest: No conflict of interest

Funding: Global Fund round 09 HIV prevention programme

Submitted: 09.11.2016, Accepted: 10.12.2016
} 


\section{Full article}

\section{Introduction}

Sri Lanka is an Island country of about 65,610 $\mathrm{km}^{2}$ located near the southern tip of India. Sri Lanka currently experience a low-level of HIV epidemic based on the fact that HIV prevalence has not consistently exceeded $5 \%$ in any of the high risk groups (HRGs) such as female sex workers (FSW), men who have sex with men (MSM), beach boys (BB) and people who inject drugs (PWID). (1) However, as of end 2015, a cumulative total of 2308 HIV positive persons have been reported to the National STD/AIDS Control Programme (NSACP), Ministry of Health, Sri Lanka. (2) During 2015, total of 235 HIV cases reported to the NSACP and it was the highest number reported in a year. In general, an estimate of 10.5 new infections occurs per week while, only about 4.5 new cases reported to the NSACP per week. (2)

During the last five years (2011-2015) relative proportion of heterosexual transmission of HIV reduced from 74\% (2011) to 54\% (2015) while proportion of male-to-male transmission increased from 20\% (2011) to $41 \%$ (2016). Mother to child transmission remained between 3-7\% over the last 5 years. Injecting drug use as a mode of transmission reported in less than $2.5 \%$ of cases. However, transmission through, blood and blood products have not been identified as a method of transmission since 2000. (2)

National Stretegic Plan (NSP) of Sri Lanka has identified different HRGs for HIV prevention interventions such as Female sex workers (FSW), men who have sex with men (MSM), beach boys (A group of men who associate with tourists as guides or animators, and provide entertainment including sexual services, majority of them are bisexuals), clients of sex workers and drug users (DU) as most-at-risk populations (MARPs). (3) The mapping and size estimation study carried out in 2013 showed that estimate of 14,132 female sex workers, 7,551 MSM, 1314 BBs, and 17,459 DU in the country. (4) HIV prevalence estimation carried out in the integrated biological and behavioural survey (IBBS) showed that HIV prevalence among FSW and MSM were $0.8 \%$ and $0.9 \%$ respectively while among DU and BB the HIV prevalence was $0 \%$.

\section{Peer group approach}

Sri Lanka has completed a phase of HIV prevention project from 2013 to 2015 (36 months) under the support of the Global Fund. The Family Planning Association of Sri Lanka (FPASL) as the non-governmental principal recipient of the GFATM grant carried out interventions targeting men who have sex with men (MSM). The main intervention is through peer group model (Fig 01). In this model, identified MSM peer educators (identified persons with knowledge and leadership qualities within peer networks) were trained and a monthly allowance was given to maintain a regular contact with another 6-15 peers forming a peer group (PG). These peer educators (PEs) were employed in different locations and overall supervision was carried out by full-time salaried field supervisors and district coordinators.

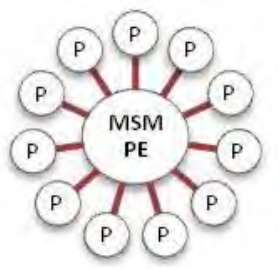

Fig 01: Peer Group $P$ - Peer (6-15 in number) MSM PE- Men who have sex with men peer educator

Peer educators are supposed to deliver an HIV prevention package (HPP) to MSM in their peer group. HIV prevention package (HPP) includes the provision of 6 components listed in the Box 1.

\section{Box 1: HIV prevention package (HPP)}
1. Provision of STI knowledge
2. Provision of HIV knowledge
3. Provision of MSM tailored leaflets
4. Condom/dildo demonstration
5. Provision of condoms and
6. Escorting of peers to STD clinic for HIV testing. 
Under this project, HPP was delivered through $248 \mathrm{MSM}$ peer educators to their peer groups covering a population of 3,638 MSM.

Peers are referred as "Reached" if the first five services are delivered (reached peers). Once the reached peers (who received all 1-5 services in the HPP) are escorted to an STD clinic they are referred as "Escorted" (escorted peers). (5)

Although escorting of MSM to the government STD clinic for HIV testing and counselling is one of the important aspects of the HIV prevention package, percentage of MSM escorted remained $23 \%$ to $39 \%$ during the past three years (2013-2015). Table 01 describe the number and percentage of MSM escorted from 2013 to 2015 against number of MSM reached with HPP (6).

Table 1: Number and percentage of MSM reached vs. escorted from 2013 to 2015.

\begin{tabular}{lrrr}
\hline Year & $\begin{array}{r}\text { Number of } \\
\text { MSM Reached } \\
\text { with HPP }\end{array}$ & $\begin{array}{r}\text { Number of } \\
\text { MSM escorted } \\
\text { to STD Clinics }\end{array}$ & $\begin{array}{r}\text { Percenta } \\
\text { ge of } \\
\text { MSM } \\
\text { escorted }\end{array}$ \\
\hline 2013 & 2127 & 496 & $23 \%$ \\
2014 & 2980 & 969 & $33 \%$ \\
2015 & 3638 & 1416 & $39 \%$ \\
\hline Source: - Annual & Progress & Report of the Primary \\
Recipient 2 (PR2) - Global Fund HIV prevention Project \\
(Round 09 Grant - Phase 2
\end{tabular}

The purpose of this paper is to analyze the factors affecting the median time-to-escort "time taken to escort" to an STD clinic. This study analyse the escorting pattern of the first year cohort (2013) who retained in the project till the end of follow-up (end December 2015)

\section{Methodology}

A cohort of MSM registered in the first year (2013) and who retained in the project till the end of December 2015 (end of follow-up) was taken for the analysis. Total of 699 MSM peers registered in the first year and retained till the end of follow-up.
Baseline data was collected at the registration of an MSM to peer groups using an interviewer administered registration form. The subsequent follow up data on the status of the delivery of components of the HPP including the escort status to an STD clinic for HIV testing were monthly recorded by PE on the Peer Calendar and sent to the community based organization (CBO) under which PEs were employed. Furthermore, re-checking of peer calendars and on site data verifications were carried out by the M\&E staff to improve data quality. The M\&E staff of the CBO feeds data to the web-based monitoring and evaluation information management system (MEIMS) maintained at the Family Planning Association of Sri Lanka (FPA)

This MEIMS maintains peer cohort from the time of peer registration with follow up data during the project period using a unique identifier called client reference number or client ID (From 2013 to end 2015). (5)

Time-to-event analysis was performed using Kaplan-Meier curves and estimates. Total of 699 MSM peers registered during the accrual period of the project (2013). Peer registration was considered as the "start of the serial time" and event was the escort step of the HIV prevention package ( $6^{\text {th }}$ step). Total of 699 serial times were analyzed using KaplanMeier estimator (KM estimator) at the end of the project period to find out median escort time with $95 \%$ confidence interval. In this study, inverse KM curve (one minus survival function) was used to understand the escorting pattern of the MSM cohort. So, the $X$ axis of the curve represent the "time to first escort" in number of months from initiation of the project and $Y$ axis represent "proportion of MSM escorted at least one time" to STD clinics for HIV testing. The oneminus survival function is referred to as the "time-to-escort function" hereafter in this paper. An important advantage of the Kaplan-Meier curve is that the method can take into account some types of "censored data" (7). In this study, censored data represent the MSM who couldn't escort at 
least one time by end of the project (December, 2015). Further, hypothesis testing (Mantel-Cox test, Generalized Wilcoxon test and Tarone-Ware test) was conducted to determine the differences in probabilities of first escort for different socio-economic and demographic characteristics. One minus survival functions (Time-to-escort functions) of different sub samples of MSM (considering socio-economic and demographic characteristics) were compared and graphically illustrated.

\section{Results}

\section{Background Information}

A total of 699 MSM peers, retained in the service cycle during the project period (20132015), were filtered out for the analysis and sample characteristics are shown in the table 02.

Table 2: Distribution of sample characteristics

\begin{tabular}{|c|c|c|c|c|}
\hline Variable & Levels & Freq & $\begin{array}{l}\text { Perce } \\
n t(\%)\end{array}$ & $\begin{array}{l}\text { Cum. } \\
\text { Perce } \\
\text { nt (\%) }\end{array}$ \\
\hline \multirow[t]{5}{*}{ District } & Colombo & 247 & $35 \%$ & $35 \%$ \\
\hline & Gampaha & 98 & $14 \%$ & $49 \%$ \\
\hline & Kalutara & 97 & $14 \%$ & $63 \%$ \\
\hline & Galle & 257 & $37 \%$ & $100 \%$ \\
\hline & Total & 699 & $100 \%$ & \\
\hline \multirow[t]{4}{*}{ Location } & Urban & 304 & $43 \%$ & $43 \%$ \\
\hline & Semi urban & 184 & $26 \%$ & $70 \%$ \\
\hline & Rural & 211 & $30 \%$ & $100 \%$ \\
\hline & Total & 699 & $100 \%$ & \\
\hline \multirow[t]{3}{*}{ Age } & $<25 y r$ & 335 & $48 \%$ & $48 \%$ \\
\hline & $\geq 25$ & 364 & $52 \%$ & $100 \%$ \\
\hline & Total & 699 & $100 \%$ & \\
\hline \multirow{6}{*}{$\begin{array}{l}\text { Marital } \\
\text { Status }\end{array}$} & Married & 125 & $18 \%$ & $18 \%$ \\
\hline & Unmarried & 514 & $74 \%$ & $92 \%$ \\
\hline & Living together & 32 & $5 \%$ & $96 \%$ \\
\hline & Divorced & 17 & $2 \%$ & $99 \%$ \\
\hline & Widow & 9 & $1 \%$ & $100 \%$ \\
\hline & Total & 697 & $100 \%$ & \\
\hline \multirow{5}{*}{$\begin{array}{l}\text { Level of } \\
\text { School } \\
\text { Education }\end{array}$} & Up to Grade 08 & 98 & $14 \%$ & $14 \%$ \\
\hline & Up to GCE O/L & 361 & $52 \%$ & $66 \%$ \\
\hline & Up to GCE $A / L$ & 205 & $29 \%$ & $95 \%$ \\
\hline & Above GCE A/L & 32 & $5 \%$ & $100 \%$ \\
\hline & Total & 696 & $100 \%$ & \\
\hline \multirow{3}{*}{$\begin{array}{l}\text { Duration } \\
\text { in MSM } \\
\text { behavior }\end{array}$} & $<5 y r$ & 173 & $25 \%$ & $25 \%$ \\
\hline & 5 to 10 & 252 & $36 \%$ & $61 \%$ \\
\hline & 10 to 20 & 228 & $33 \%$ & $94 \%$ \\
\hline \multirow{2}{*}{$\begin{array}{l}\text { (No of } \\
\text { years) }\end{array}$} & $>20 y r$ & 43 & $6 \%$ & $100 \%$ \\
\hline & Total & 696 & $100 \%$ & \\
\hline
\end{tabular}

\section{Time-to-escort analysis}

Out of the 699 serial times, 499 MSM peers (71.4\%) had completed the event of interest (escort step) at least one time by the end of the project period (secular time). The remaining MSM (28.6\%) who have not been escorted at least one time were presented as "Censored" in KM curves. Estimated median time-to-escort was 17 months (SD $=0.867$ months). In other words, as an estimate, only $50 \%$ of the MSM peers have been escorted to the STD clinics during the first 17 months (95\% Cl $=15.3-18.7$ months) of the project.

Time-to-escort analysis by district of project implementation

Figure 1: Time-to-escort functions by districts

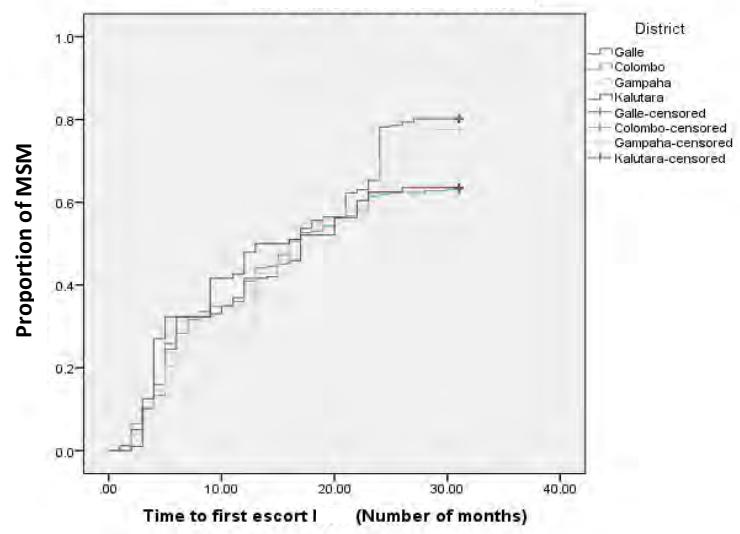

(Generalized Wilcoxon test $\mathrm{P}=0.534, \mathrm{X}^{2}=2.1920$ and TaroneWare test $\left.P=2610, X^{2}=4.006\right)$.

As shown in the figure 1, the time-to-escort functions of different districts are significantly different, showing a high escort rates in Galle and Gampaha by end of the project (log rank test $P=0.033, X^{2}=0.050$ ). Although, there is no statistically significant difference in escort rates among four districts in the first half of the project, Kalutara district has performed over other districts during the first half. So, lowest median time to first escort was recorded in Kalutara (13 months) followed by Colombo (16 months), Gampaha (16 months) and Galle (17 months). 
Time-to-escort analysis by sociodemographic and behavioural factors

Escorting of MSM peers for an STD clinic is depend on many factors. In the secular time period of the study(2013-2015), some MSM showed relatively more median time-toescort. They included, Non-youth MSM ( $>25$ years), educated MSM (> GCE O/L), rural MSM, Nachchi MSM (effeminate males), MSM with more frequent receptive anal sex ( $>7$ week), long duration MSM (>10 years).

Other groups of MSM showed less medium time-to-escort (more likely to escort). They included, generally young MSM (<25 years), Less educated MSM (up to GCE O/L), noneffeminate MSM, urban and semi-urban MSM (Table 3)

Table 3: Distribution of estimated median time-to-escort and hypothesis tests by socio-demographic factors and behavioural factors

\begin{tabular}{|c|c|c|c|c|c|c|c|c|}
\hline \multirow{3}{*}{ Variable } & & \multirow{3}{*}{ Levels } & \multicolumn{3}{|c|}{$\begin{array}{l}\text { Estimated Median time- } \\
\text { to-escort (months) }\end{array}$} & \multicolumn{2}{|c|}{$\begin{array}{l}\text { Hypothesis tests for } \\
\text { time-to-escort }\end{array}$} & equality of \\
\hline & & & \multirow[t]{2}{*}{ Months } & \multicolumn{2}{|c|}{$\begin{array}{l}\text { 95\% Confidence } \\
\text { Interval }\end{array}$} & \multirow{2}{*}{$\begin{array}{l}\text { Breslow } \\
\text { (Generalized } \\
\text { Wilcoxon) } \\
\text { Early part of } \\
\text { the curve }\end{array}$} & \multirow{2}{*}{$\begin{array}{l}\begin{array}{l}\text { Tarone- } \\
\text { Ware }\end{array} \\
\begin{array}{l}\text { Middle part } \\
\text { of the curve }\end{array} \\
\end{array}$} & \multirow{2}{*}{$\begin{array}{l}\begin{array}{l}\log \text { Rank } \\
\text { (Mantel-Cox) }\end{array} \\
\text { Latter part of } \\
\text { the curve }\end{array}$} \\
\hline & & & & $\begin{array}{l}\text { Lower } \\
\text { bound }\end{array}$ & $\begin{array}{l}\text { Upper } \\
\text { bound }\end{array}$ & & & \\
\hline \multirow{15}{*}{$\begin{array}{l}\text { Socio- } \\
\text { demographic } \\
\text { factors }\end{array}$} & Age (years) & Youth & 16 & 13.096 & 18.904 & \multirow{3}{*}{$\begin{array}{l}X^{2}=3.389 \\
P=0.066\end{array}$} & \multirow{3}{*}{$\begin{array}{l}X^{2}=4.194 \\
P=0.041^{*}\end{array}$} & \multirow{3}{*}{$\begin{array}{l}X^{2}=5.098 \\
P=0.024^{*}\end{array}$} \\
\hline & Youth: $<25$ yrs & Non-youth & 17 & 14.564 & 19.436 & & & \\
\hline & Non-youth: $\geq 25$ yrs & Overall & 17 & 15.300 & 18.700 & & & \\
\hline & \multirow[t]{3}{*}{ Level of Education } & Up to GCE $O / L$ & 16 & 14.412 & 17.588 & \multirow{3}{*}{$\begin{array}{l}X^{2}=3.420 \\
P=0.064\end{array}$} & \multirow{3}{*}{$\begin{array}{l}X^{2}=3.964 \\
P=0.046^{*}\end{array}$} & \multirow{3}{*}{$\begin{array}{l}X^{2}=4.201 \\
P=0.040^{*}\end{array}$} \\
\hline & & $\begin{array}{l}\text { Above GCE } \\
O / L\end{array}$ & 20 & 16.707 & 23.293 & & & \\
\hline & & Overall & 17 & 15.180 & 18.820 & & & \\
\hline & \multirow[t]{3}{*}{ Marital Status } & Ever Married & 16 & 13.264 & 18.736 & \multirow{3}{*}{$\begin{array}{l}X^{2}=0.000 \\
P=0.984\end{array}$} & \multirow{3}{*}{$\begin{array}{l}X^{2}=0.012 \\
P=0.913\end{array}$} & \multirow{3}{*}{$\begin{array}{l}X^{2}=0.060 \\
P=0.807\end{array}$} \\
\hline & & Other & 17 & 14.824 & 19.176 & & & \\
\hline & & Overall & 17 & 15.280 & 18.720 & & & \\
\hline & \multirow{3}{*}{$\begin{array}{l}\text { Location of the hot } \\
\text { spot }\end{array}$} & Rural & 17 & 13.841 & 20.159 & \multirow{3}{*}{$\begin{array}{l}X^{2}=2.666 \\
P=0.103\end{array}$} & \multirow{3}{*}{$\begin{array}{l}X^{2}=3.424 \\
P=0.064\end{array}$} & \multirow{3}{*}{$\begin{array}{l}X^{2}=4.580 \\
P=0.032^{*}\end{array}$} \\
\hline & & Urban/Semi & 16 & 13.763 & 18.237 & & & \\
\hline & & Overall & 17 & 15.300 & 18.700 & & & \\
\hline & \multirow[t]{3}{*}{ MSM Category } & Nachchi & 20 & 13.185 & 26.815 & \multirow{3}{*}{$\begin{array}{l}X^{2}=1.300 \\
P=0.254\end{array}$} & \multirow{3}{*}{$\begin{array}{l}X^{2}=2.227 \\
P=0.136\end{array}$} & \multirow{3}{*}{$\begin{array}{l}X^{2}=3.454 \\
P=0.043^{*}\end{array}$} \\
\hline & & Other MSM & 16 & 14.528 & 17.472 & & & \\
\hline & & Overall & 17 & 15.330 & 18.670 & & & \\
\hline Behavioural & Frequent & Less than 7 & 16 & 12.444 & 19.556 & $X^{2}=10.513$ & $x^{2}=9.257$ & $X^{2}=7.799$ \\
\hline factors & receptive anal sex & 7 and above & 22 & 19.143 & 24.857 & $P=0.001^{*}$ & $P=0.002 *$ & $P=0.005^{*}$ \\
\hline & per week & Overall & 18 & 15.348 & 20.652 & & & \\
\hline & Frequent of & Less than 7 & 17 & 15.293 & 18.707 & $X^{2}=0.350$ & $X^{2}=0.209$ & $X^{2}=0.062$ \\
\hline & insertive anal sex & 7 and above & 13 & 10.119 & 15.881 & $P=0.554$ & $P=0.648$ & $P=0.804$ \\
\hline & per week & Overall & 16 & 14.394 & 17.606 & & & \\
\hline & Duration of MSM & $<10$ years & 16 & 13.912 & 18.088 & $X^{2}=2.159$ & $x^{2}=3.170$ & $X^{2}=4.419$ \\
\hline & behavior & $\geq 10$ years & 17 & 13.976 & 20.024 & $P=0.142$ & $P=0.05^{*}$ & $P=0.036^{*}$ \\
\hline & & Overall & 17 & 15.180 & 18.820 & & & \\
\hline & Test for HIV before & Yes & 16 & 14.254 & 17.746 & $X^{2}=1.985$ & $X^{2}=2.480$ & $X^{2}=2.941$ \\
\hline & joining with the & No & 22 & 16.852 & 27.148 & $P=0.159$ & $P=0.115$ & $P=0.086$ \\
\hline & program & Overall & 17 & 15.180 & 18.820 & & & \\
\hline
\end{tabular}




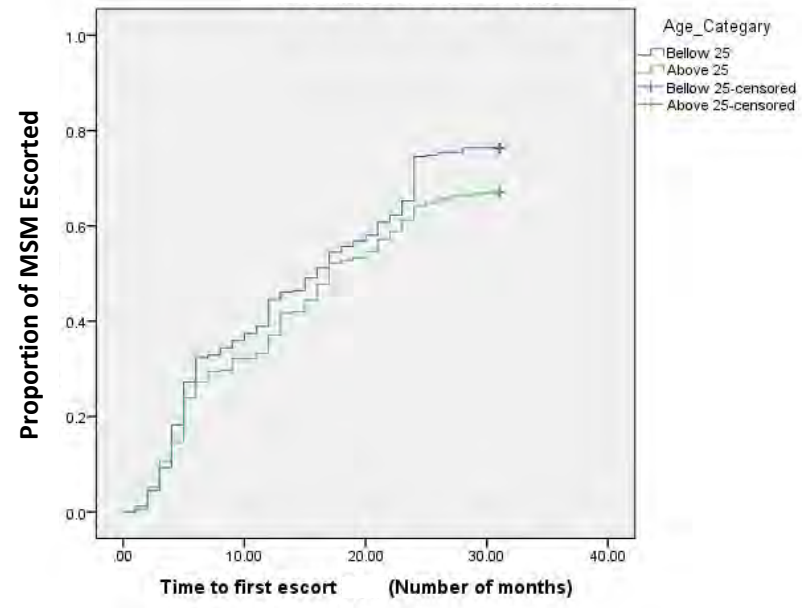

Figure 2: Cumulative Escort distributions for youth and non-youth MSM

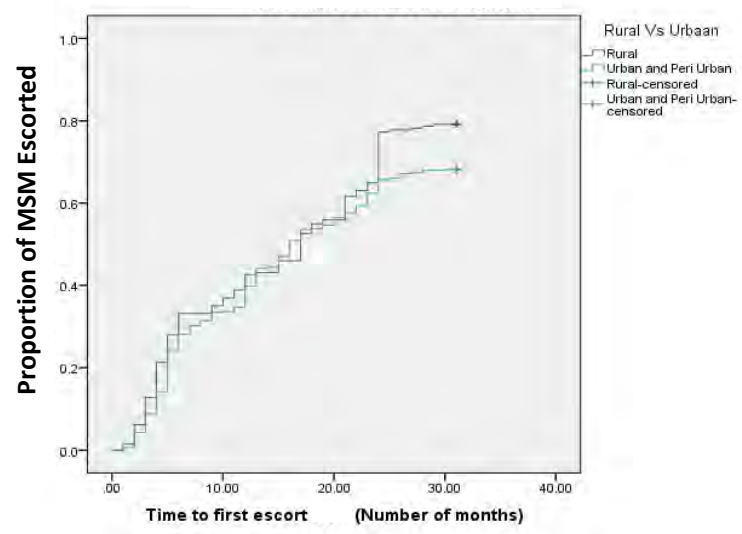

Figure 4: Cumulative Escort distributions for MSM living in rural and urban area

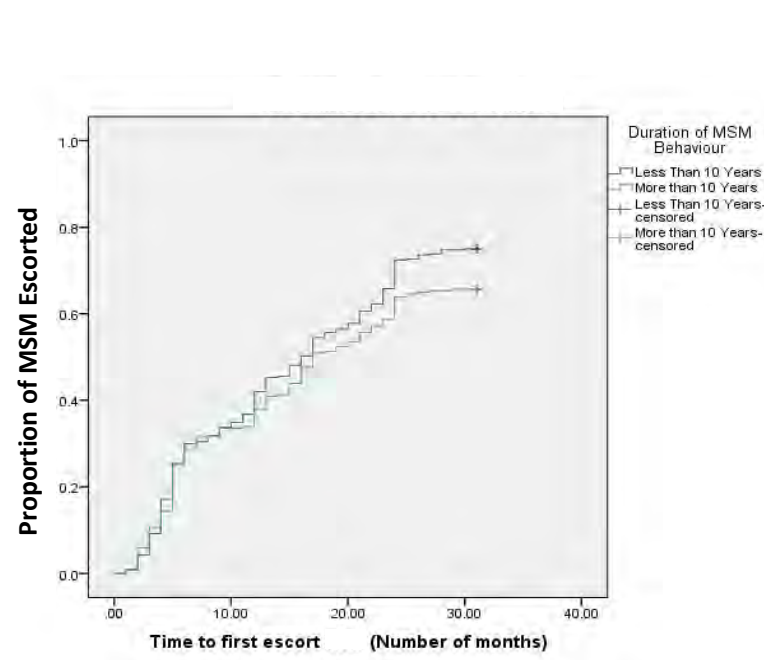

Figure 6: Cumulative escort vs duration of MSM behaviour ( $<10$ vears and $\geq 10$ vears)

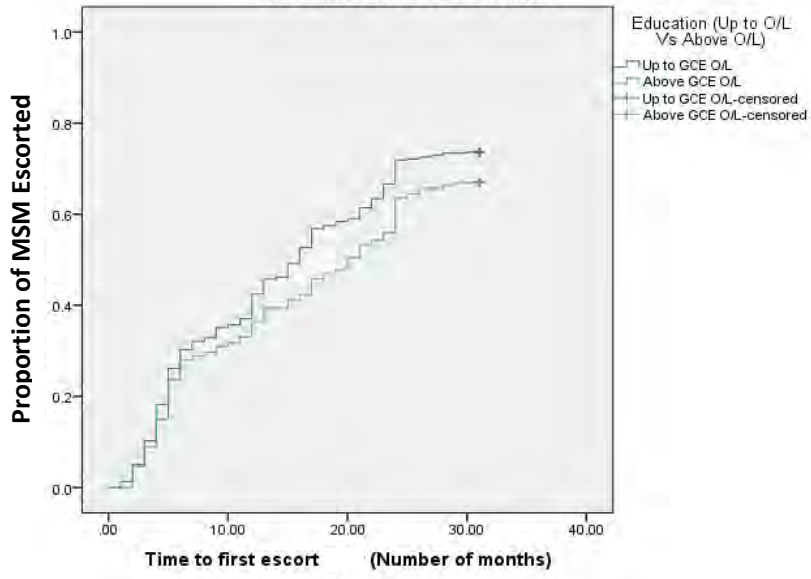

Figure 3: Cumulative Escort distributions for high educated and less educated MSM

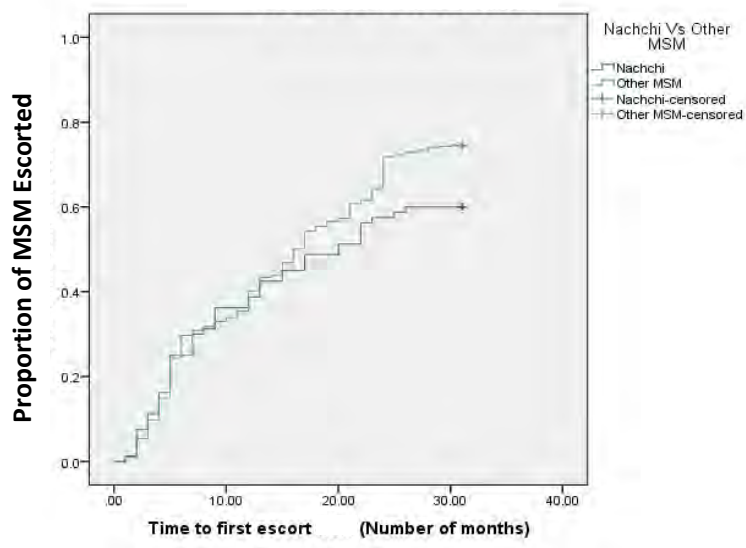

Figure 5: Cumulative Escort distributions for Nachchi and other MSM

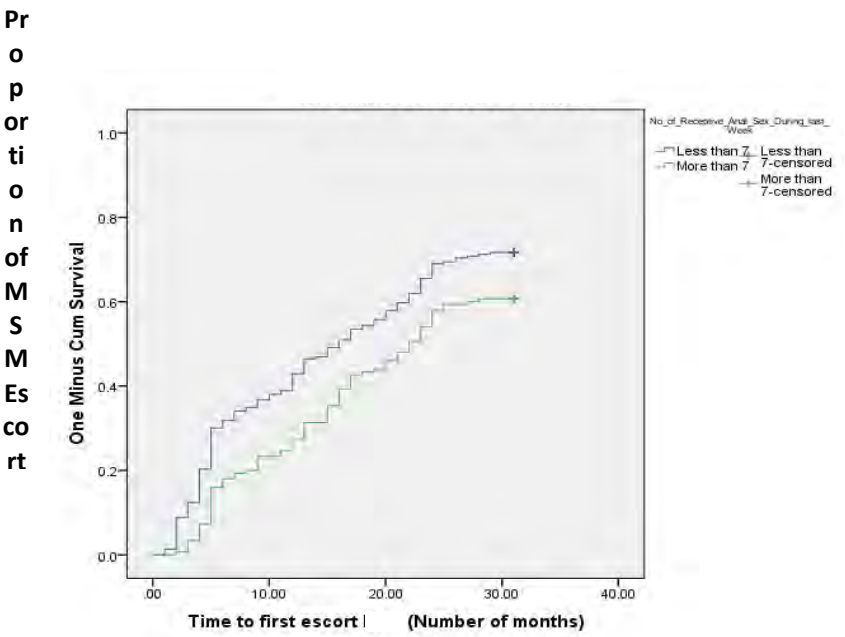

Figure 7: Cumulative Escort distributions by number of receptive anal sex 


\section{Discussion}

A previous cross sectional analysis conducted using the sample of MSM found that the clinic $(P<0.001)$, duration of MSM behaviour $(P=0.018)$, experience of an HIV test during previous 12 months $(P=0.050)$, number of receptive anal sex $(P=0.050)$. (8)

In this study, time-to-escort analysis and hypothesis testing for equality of escort functions shows that some groups take long time to be escorted to an STD clinic. Those groups include high frequent receptive MSM ( $\geq 7 /$ week), MSM who never had an HIV test (before project enrolment), educated MSM and Nachchi MSM (effeminate MSM). Furthermore, Peer educators have taken about 17 months to escort Non-youth MSM, rural MSM, low frequent insertive MSM $(<7 /$ week) and MSM with $\geq 10$ years behaviour. Therefore, different innovative strategies need to be adopted to increase the rate of HIV testing among those who take longer time-to-escort.

High frequent receptive MSM ( $\geq 7 /$ week) and Nachchi MSM (effeminate MSM) are less likely to be escorted by peer educators. Nachchi MSM also includes male sex workers (MSW) and most of them practice receptive anal sex. Receptive anal sex and effeminate nature of Nachchi MSM have self and felt stigma which made them to be escorted less likely.

MSM who never had an HIV test before the enrolment to the project seems to be still difficult to be escorted for an HIV test may be due to some personal or access related barrier.

Furthermore, non-youth MSM and long duration MSM ( $\geq 10$ years) are also taking relatively long time-to-escort may be due to some experience based personal attitude.

Although it is not statistically significant, low frequent insertive MSM (<7/week) are more difficult to be escorted than high frequent escort is associated with age group of MSM $(P=0.008)$, level of education $(P=0.007)$, urban/rural status

insertive MSM ( $\geq 7 /$ week) probably due to the fact that low frequent insertive MSM are reluctant to disclose the homosexual behaviour at STD clinics. In this analysis, rural MSM were also needed long time-to-escort which may be due to stigma and distance related factors.

Overall, these results indicate that MSM with higher risk of HIV take longer time for the first escort and are less likely to be escorted for HIV testing. As shown in the graphical illustrations, and results of the hypothesis testing, this difference is higher and significant in the middle and later part of the project. Apart from the socio-demographic and behavioural factors, pressure imposed on peer educators by the project management to achieve the escort targets may affect on higher rate of escorts of low risk MSM who are easy to escort for HIV testing. This programme quality gap may increase by introducing strategies such as incentivising the peer educators on their performance, by setting unrealistic targets.

In addition, it has been observed that district variation of escort rates are also largely depend on the district level implementation (CBO), performance of $\mathrm{PE}$, field supervisors and coordinators who can overcome some of the difficulties found. These lesson learnt needs to be considered in designing and implementing of future HIV prevention interventions for MSM.

\section{Conclusion}

Escorting of MSM peers to an STD clinic is depending on many factors. The estimated median time-to-escort an MSM peer was 17 months from the start of the project.

Time-to-escort functions of different districts are significantly different, showing a high escort rates in Galle and Gampaha towards the end of the project, there is no significant 
difference in escorts among four districts in the first half of the project. This shows the differences of efficiency of implementation of the project by the staff of the CBOs. Efficiency is significant at the latter part of the project most probably due to the time, target and incentive bound programmatic pressure of the project.

Relatively longer time has been taken for peer educators to escort high frequent receptive MSM (22 months) and MSM who never had an HIV test (22 months). A median of about 20 months has been taken to escort educated MSM and Nachchi MSM. Furthermore, it has been taken about 17 months to escort nonyouth MSM, rural MSM, low frequent insertive MSM (<7/week).

Relatively shorter period (13 months) has been taken by peer educator to escort high frequent insertive MSM ( $\geq 7 /$ week) probably due to their self acceptance of homosexual behaviours and more masculine nature of the behaviour.

Generally, more attention and tailored interventions are necessary to improve escort rates among MSM who needed longer timeto-escort to an STD clinic for HIV testing because they are less likely to be escorted. Current intervention need to be strengthened with more focus strategies to address this programmatic gap. In addition, performances of PEs, field supervisors and coordinators have been observed to be a major factor in improving escort rate.

\section{References}

1. UNAIDS/WHO. Guidelines for second generation HIV surveillance. World Health Organization. Geneva : s.n., 2000.

2. NSACP/MoH. Annual Report 2015. National STD/AIDS Control Programme, Ministry of Health. Colombo : s.n., 2016.

3. National STD/AIDS Control Programmes. National Strategic Plan 2013-2017. National STD/AIDS Control Programme, Ministry of Health. Colombo : s.n., 2013.

4. National STD/AIDS Control Programme. National size estimation of most-at-risk populations (MARPs) for HIV in Sri Lanka. National STD/AIDS Control Programme, Ministry of Health. Colombo : National STD/AIDS Control Programme, 2013.

5. Family Planning Association of Sri Lanka. Monitoring and Evaluation Plan, Glonal Fund round 9 HIV prevention project (Phase II). Family Planning Association of Sri Lanka. Colombo: s.n., August 2013.

6. The Family Planning Association of Sri Lanka. Annual Progress Report of the PR2 - Global Fund HIV prevention Project (Round 09 Grant - Phase 2). Colombo: Monitoring and Evaluation Unit - The Family Planning Association of Sri Lanka, 20132015.

7. Nonparametric estimation from incomplete observations. Kaplan, L E and Meier, P. [ed.] John Tukey. 282, 1958, Journal of the American Statistical Association, Vol. 53, pp. 457-481.

8. Factors associated with clinic escorts in peer-led HIV prevention interventions for men who have sex with men (MSM) in Sri Lanka. Suranga, M Suchira, et al.

9. UNAIDS, WHO Working Group. Guideline for second generation HIV surveillance: an update: Know your epidemic. World Health Organization. Geneva : s.n., 2013. 